\title{
Neural Network based Forecasting Model for Natural Gas Consumption
}

\author{
Prabodh Kumar Pradhan \\ Assistant Professor \\ RCMA, CS Pur \\ Bhubaneswar 751023 India
}

\author{
Sunil Dhal \\ Associate Professor \\ Sri Sri University \\ Cuttack 754006 India
}

\author{
Nilayam Kumar Kamila \\ Principal Associate \\ Capital One, Wilmington, \\ DE 19801 USA
}

\begin{abstract}
Natural resource is a limited resource and its utilization with proper planning is utmost important for human being. Natural gas is one of the highly consumed natural resource which requires a proper planning and utilization. Environmental factor such as temperature, humidity is few of the factors which effect the natural gas consumption. In this paper, the consumption of natural gas is evaluated with respect to environmental factors through neural network based approach and compared the forecasting results. The analysis results and comparison model show the better results and could be used in forecasting of the future natural gas consumption.
\end{abstract}

\section{General Terms}

Neural Networks, Forecasting

\section{Keywords}

Natural Gas, Natural Gas Consumption, Consumption factors

\section{INTRODUCTION}

Natural Gas Consumption (NGC) is now a vital and important area where planning of the NGC is very much required. The consumption forecasting solely provides an input to the Natural Gas production unit where the cost of production and transportation will be minimized. Moreover, it's a natural resource and conservation of natural resource is the primary concerns of every nations and its government. The accurate model of forecasting is still a challenge and very few research are rolled in for this subject area. The extraction process [1] is very complex process and lots of effort and money are invested for the extraction of this natural gas. The nation like INDIA, where the subsidy is invested from Government for this natural gas extraction and transportation to make it available to common man with subsidized price, it's very much required to obtain a good model for forecasting the natural gas consumption. There are many classical models available e.g. moving average, smoothing analysis, least square model where the forecasting is made with close proximity to the actual consumption. In this article, a specific neural network based model is proposed which is used to find the accuracy of consumption and the data is compared with the existing mathematical model.

The organization of this article is as follows. The general introduction of neural network is discussed in section 3.0. Section 4 and 5 , the proposed model is described. The simulation data and normalization data are provided in following section i.e. section 6. Section 7 includes proposed model simulation analysis and followed by conclusion.

\section{RELATED WORK}

Authors of [1] has predicted the classical models e.g. Time Series, ARIMA (Auto Regressive Moving Average) and defined the forecasting of Natural Gas consumption as best fit model. In [3], authors have overviewed different mathematical model and neural network model. The classical model e.g. ARIMA model has been implemented and shown the absolute mean error rate is approximated between 6-10\% error. Different factors effecting the natural gas consumption is discussed and are as follows.

Temperature: Temperature has the effect on natural gas consumption as it makes the gas heat and volume expansion effect.

Wind effects: Wind has the effect for the gas consumption because every object lose heat and energy more faster in windy day [2].

Other factors: Solar radiation, cloud cover, precipitation, dew points [2] are other several factors which affects the natural gas consumption.

In overall, there are few classic models implemented with an error rate 6-10 and the neural network model implementation is never attempted. We extensively study the environmental factors and proposed the neural network based natural gas consumption forecasting evaluation model which discussed in this subsequent section of this article.

\section{NEURAL NETWORK MODEL}

\subsection{General Overview}

Neural Network model is a model which exactly an image replication of out brain. In our brain, there are many neurons which simulates and generates a decision output and based on which our body organs acted upon. In similar fashion, in neural network model, it comprises of several network layers. In below figure, there are typically 3 layers, e.g. input layer, hidden layer and output layer are shown. There could be more hidden layers to make the neural network model accuracy. Each layer is made up of interconnected nodes and it contains an activation function. The real-time patterns are submitted to the input layer, this input layer then communicates to the one or several hidden layers. Each connection is associated with the weight which is helps to evaluates the values of the pattern at hidden layers and finally hidden layer communicates to output layer where the pattern output is resulted and based on an activation function, the result is translated to the calculated pattern which then compared to the expected pattern. 


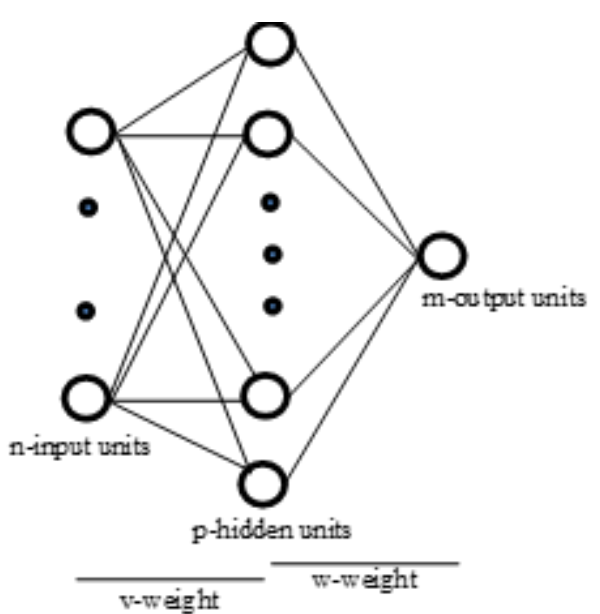

\subsection{Neural Network Model for NGC}

In case of Natural Gas(NGC) consumption, three parameters have been taken to evaluate the patterns of the consumption. These are described as below.

Humidity (Sea Pressure) Data: Humidity is playing a role for the human body digestive system [4]. This also makes the human psychology to feel differently which makes the human body to work actively or makes body tired. This in turn makes the NGC to be dependent on.

All these factors are not in the scope picture where the forecasting made on the classical model e.g. moving average, least square methods. As these factors have a great impact on the natural gas consumption, a system model is proposed which considers the NGC effective environmental factors to forecast the consumption. The system then compared with the classical model to evaluate the difference.

Fig 1: Neural Network Layered Structure

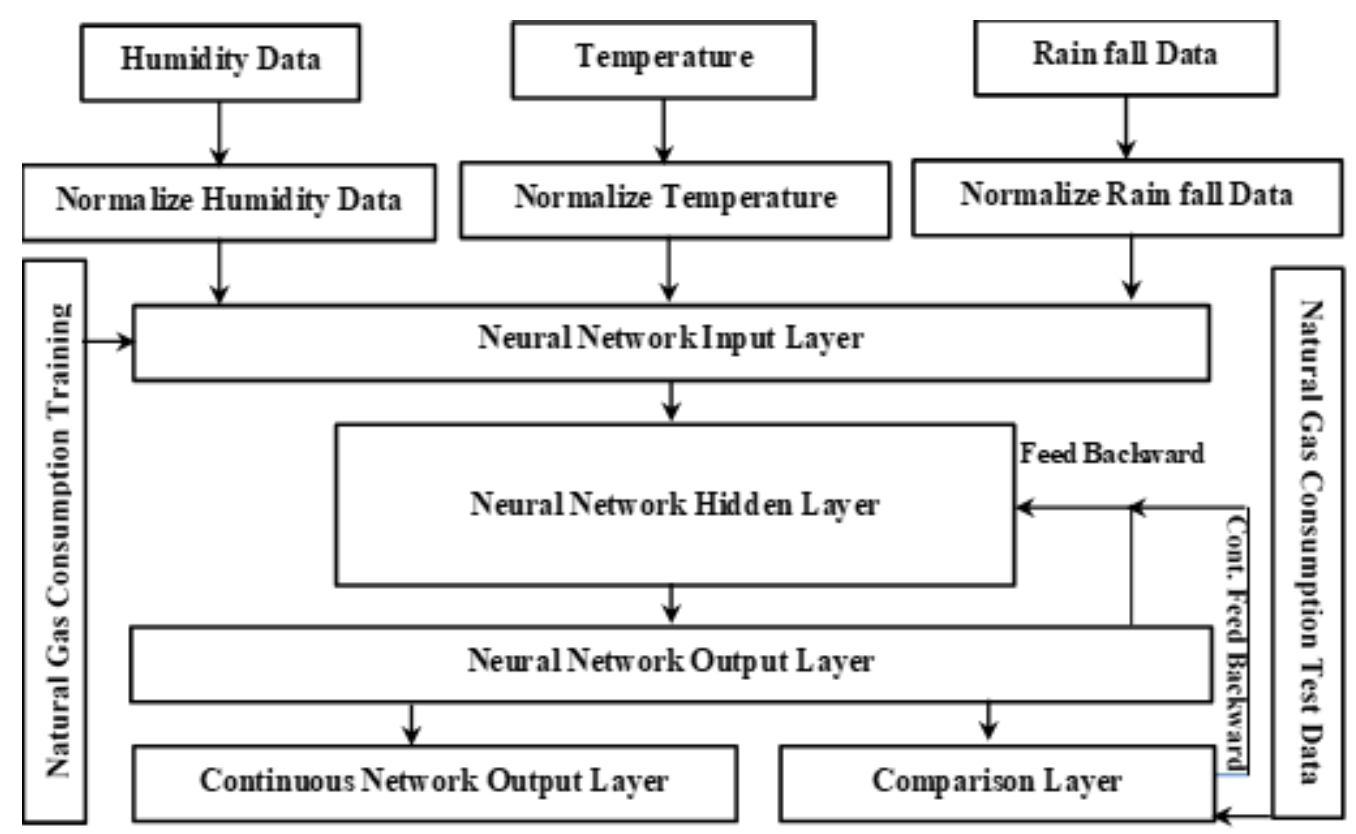

Fig 2: NN based NGC System Model

Temperature: Temperature always play a main role in daily activity. In cold geographical regions, there are certainly low energy loss from human body and in high temperature geographic region, there are high energy loss. In a specific region, the seasonal cycle has a direct effect on NGC. The food preparation style and the life style of human changes based on the seasonal changes. In factories, the NGC is also affected due to the temperature changes throughout the year.

Rainfall: Rainfall is another environmental factor which inherently affect the natural gas consumption. Rainfall makes the human body metabolism slower [6] and hence the food style is greatly affected. There are several works affected due to rainfall, and hence the NGC also less consumed. Most of the natural gas based vehicle are off-work due to the slight/heavy rain fall and this results a less consumption of natural.

\section{PROPOSED NEURAL NETWORK BASED NGC MODEL}

In this article, a Neural Network(NN) based Natural Gas Consumption(NGC) model is presented, where 3 environmental factors e.g. Temperature, Humidity (Sea Level Pressure) and Rainfall of the area have been taken into consideration and NGC is analyzed. This model has several steps as discussed below.

1. Input Data Normalization:

2. Feed to Neural Network Layer

3. Processing in Neural Network

4. Output and Comparison Process

Let's discuss each steps of our proposed model.

Input Data Normalization: In this step, humidity data, temperature data and rainfall data have been normalized. This 
normalization provides the final data in a scale of $0 \leq$ data $\leq$ 1.

Feed to Network Layer: The resulted normalized data then fed to the network layer. As discussed in previous section, the data is fed to the input layer of neural network. As there are 3-input data e.g. temperature, humidity and rainfall are considered in scope, so the number of nodes in the input layer is 3 .

Processing in Neural Network: In this layer, the data fed into the input layer is communicated to the hidden layer through the associated weighted connections. There could be several number of input layers, but for simplicity, only one hidden layer is considered to evaluate the output pattern.

Output and Comparison Process: This is the most important part of our integrated NN based NGC Engine. The output of the hidden layer then posted to the output layer with the weighted connection. Each transmitted communication then activated through an activation function and the result is evaluation. The resulted output is again compared with the expected result and feed backward to the NN based NGC engine to adjust the network connections values. This will make the weight of the connection so accurately, that it'll make the next result to a slight more accuracy with the expected output. This NN evaluation process with back forwarding result to adjust the connection weight is called as Backward Propagation Network. In this way after a several repetitive processes, the result will be come close proximity accuracy with the expected result.

Neural Network with Backpropagation Network methodology is used as the NGC engine in the proposed model. The following input vectors and other parameters have been taken for processing the network data.

$$
\begin{aligned}
& x=\text { input training vector } \\
& t=\text { output target vector } \\
& \alpha=\text { learning rate parameter } \\
& v_{0 j}=\text { weight on } j^{t h} \text { hidden unit } \\
& w_{0 k}=\text { weight on } k^{t h} \text { output unit } \\
& \epsilon=\text { error vector }
\end{aligned}
$$

At the initial steps, the input data e.g. humidity, temperature and rainfall data is normalized as discussed in previous section. Then the algorithm repeats till the error is less than a constant i.e. $\epsilon_{k}$ or to a maximum epoch period, say 10000 . The error is the difference between the calculated output and the expected output i.e. $\partial t_{k}=t_{k}-y_{k}$. The output of the $j^{t h}$ hidden unit is calculated as below.

$$
z_{j}=f\left(v_{0 j}+\sum_{i=1}^{n} x_{i} v_{i j}\right)
$$

Similarly, the output of the $k^{\text {th }}$ output unit is calculated as below.

$$
y_{k}=f\left(w_{0 k}+\sum_{j=1}^{p} z_{j} w_{j k}\right)
$$

The error correction factor between output and hidden layer is calculated as,

$$
\begin{aligned}
\delta_{k}=\left(t_{k}-y_{k}\right) f^{\prime}\left(w_{0 k}+\sum_{j=1}^{p} z_{j} w_{j k}\right) \\
\Delta w_{j k}=\propto \delta_{k} z_{j} \quad \text { and } \\
\Delta w_{0 k}=\propto \delta_{k}
\end{aligned}
$$

Similarly, the error correction factor between hidden and input layer is calculated as,

$$
\begin{aligned}
\delta_{j} & =\left(\sum_{k=1}^{m} \delta_{k} w_{j k}\right) f^{\prime}\left(v_{0 j}+\sum_{i=1}^{n} x_{i} v_{i j}\right) \\
\Delta v_{i j}=\propto \delta_{j} x_{i} \quad \text { and } & \\
\Delta v_{0 j} & =\propto \delta_{j}
\end{aligned}
$$

Finally, the updates of the weights are calculated as follows.

$$
w_{j k}=w_{j k}+\Delta w_{j k} \text { and } v_{i j}=v_{i j}+\Delta v_{i j}
$$

The algorithm for the neuralnetworkNGCEngine is shown in previous page.

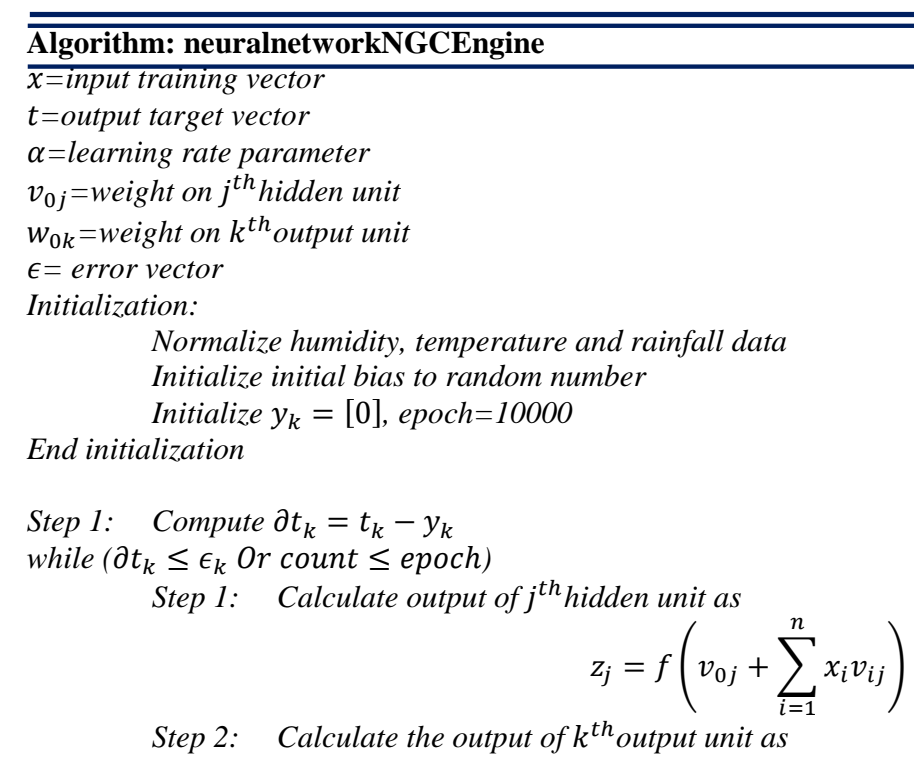




$$
\begin{aligned}
& y_{k}=f\left(w_{0 k}+\sum_{j=1}^{p} z_{j} w_{j k}\right) \\
& \text { Step 3: Compute the error correction factor between output and hidden layer } \\
& \delta_{k}=\left(t_{k}-y_{k}\right) f^{\prime}\left(w_{0 k}+\sum_{j=1}^{p} z_{j} w_{j k}\right) \\
& \Delta w_{j k}=\propto \delta_{k} z_{j} \text { and } \Delta w_{0 k}=\propto \delta_{k} \\
& \text { Step 4: Compute the error correction factor between hidden and input layer } \\
& \delta_{j}=\left(\sum_{k=1}^{m} \delta_{k} w_{j k}\right) f^{\prime}\left(v_{0 j}+\sum_{i=1}^{n} x_{i} v_{i j}\right) \\
& \Delta v_{i j}=\propto \delta_{j} x_{i} \text { and } \Delta v_{0 j}=\propto \delta_{j}
\end{aligned}
$$

$$
w_{j k}=w_{j k}+\Delta w_{j k} \text { and } v_{i j}=v_{i j}+\Delta v_{i j}
$$

\section{SIMULATION DATA}

There are three years data have been captured for this Neural Network based Natural Gas Consumption. The complete data for year-wise i.e. 2012, 2013 and 2014 is shown below.

\subsection{Natural Gas Consumption Data}

The tabular data is captured from [4] month-wise for the year 2012, 2013 and 2014 for the domestic area of Bhubaneswar, State capital of Odisha. The year wise natural gas consumption normalized data calculated as per the following formula.

$$
\left\|C_{r}^{m_{i}}\right\|=\frac{C_{r}^{m_{i}}}{\operatorname{Max}\left(C_{r}^{m_{1}}, C_{r}^{m_{2}} \ldots C_{r}^{m_{12}}\right)}
$$

Where $\left\|C_{r}^{m_{i}}\right\|$ is the average of Consumption for the month of $m_{i}$ for the region $r$. Here $r$ is Bhubaneswar, State Capital of Odisha, INDIA.

\section{Table 1. Natural Gas Consumption Data for Y12-Y14}

\begin{tabular}{|l|l|l|l|}
\hline \multicolumn{1}{|c|}{ Month } & Year 2012 & \multicolumn{1}{c|}{ Year 2013 } & Year 2014 \\
\hline Jan & 16425 & 16449 & 20174 \\
\hline Feb & 16293 & 15409 & 18531 \\
\hline Mar & 16682 & 17732 & 21205 \\
\hline Apr & 14850 & 16092 & 18250 \\
\hline May & 17098 & 16428 & 18831 \\
\hline Jun & 16348 & 15259 & 18039 \\
\hline Jul & 17413 & 18287 & 20233 \\
\hline Aug & 17848 & 17715 & 21142 \\
\hline Sep & 17123 & 17047 & 22570 \\
\hline Oct & 16610 & 18412 & 21581 \\
\hline Nov & 16824 & 19536 & 22941 \\
\hline Dec & 16648 & 19030 & 25350 \\
\hline
\end{tabular}

The normalized NGC data calculated from above equation is shown in below table.

Table 2. Normalized NGC Data for Y12-Y14

\begin{tabular}{|l|c|c|c|}
\hline Month & Norm Y12 & Norm Y13 & Norm Y14 \\
\hline Jan & 0.920271179 & 0.841984029 & 0.79581854 \\
\hline Feb & 0.912875392 & 0.788748976 & 0.731005917 \\
\hline Mar & 0.934670551 & 0.907657658 & 0.836489152 \\
\hline Apr & 0.832025997 & 0.823710074 & 0.719921105 \\
\hline May & 0.957978485 & 0.840909091 & 0.742840237 \\
\hline Jun & 0.91595697 & 0.781070844 & 0.711597633 \\
\hline
\end{tabular}

\begin{tabular}{|l|l|l|l|}
\hline Jul & 0.975627521 & 0.936066749 & 0.798145957 \\
\hline Aug & 1 & 0.906787469 & 0.834003945 \\
\hline Sep & 0.959379202 & 0.872594185 & 0.890335306 \\
\hline Oct & 0.930636486 & 0.942465192 & 0.851321499 \\
\hline Nov & 0.942626625 & 1 & 0.904970414 \\
\hline Dec & 0.932765576 & 0.974099099 & 1 \\
\hline
\end{tabular}

\subsection{Temperature Data}

The tabular data is captured from [14] month-wise for the region of Bhubaneswar, State capital of Odisha. The year wise normalized temperature data calculated as per the following formula.

$$
\left\|T_{r}^{m_{i}}\right\|=\frac{T_{r}^{m_{i}}}{\operatorname{Max}\left(T_{r}^{m_{1}}, T_{r}^{m_{2}} \ldots T_{r}^{m_{12}}\right)}
$$

Where $\left\|T_{r}^{m_{i}}\right\|$ is the average of Temperature for the month of $m_{i}$ for the region $r$. Here $r$ is Bhubaneswar, State Capital of Odisha, INDIA.

Table 3. Temperature Data for Y12-Y14

\begin{tabular}{|l|l|l|l|}
\hline \multicolumn{1}{|c|}{ Month } & Year 2012 & Year 2013 & Year 2014 \\
\hline Jan & 78 & 84 & 84 \\
\hline Feb & 75 & 90 & 90 \\
\hline Mar & 101 & 100 & 95 \\
\hline Apr & 101 & 102 & 104 \\
\hline May & 102 & 101 & 102 \\
\hline Jun & 99 & 94 & 97 \\
\hline Jul & 89 & 89 & 88 \\
\hline Aug & 90 & 90 & 91 \\
\hline Sep & 90 & 90 & 89 \\
\hline Oct & 90 & 86 & 88 \\
\hline Nov & 85 & 86 & 87 \\
\hline Dec & 86 & 84 & 81 \\
\hline
\end{tabular}

The normalized Temperature data calculated from above equation is shown in below table.

Table 4. Normalized Temperature Data for Y12-Y14

\begin{tabular}{|l|l|l|l|}
\hline Month & Norm Y12 & \multicolumn{1}{c|}{ Norm Y13 } & Norm Y14 \\
\hline Jan & 0.764705882 & 0.823529412 & 0.807692308 \\
\hline Feb & 0.735294118 & 0.882352941 & 0.865384615 \\
\hline Mar & 0.990196078 & 0.980392157 & 0.913461538 \\
\hline Apr & 0.990196078 & 1 & 1 \\
\hline May & 1 & 0.990196078 & 0.980769231 \\
\hline
\end{tabular}




\begin{tabular}{|l|l|l|l|}
\hline Jun & 0.970588235 & 0.921568627 & 0.932692308 \\
\hline Jul & 0.87254902 & 0.87254902 & 0.846153846 \\
\hline Aug & 0.882352941 & 0.882352941 & 0.875 \\
\hline Sep & 0.882352941 & 0.882352941 & 0.855769231 \\
\hline Oct & 0.882352941 & 0.843137255 & 0.846153846 \\
\hline Nov & 0.833333333 & 0.843137255 & 0.836538462 \\
\hline Dec & 0.843137255 & 0.823529412 & 0.778846154 \\
\hline
\end{tabular}

\subsection{Humidity/Sea Pressure Data}

The tabular data is captured from [14] month-wise for the region of Bhubaneswar, State capital of Odisha. The year wise normalized Humidity/Sea Pressure data calculated as per the following formula.

$$
\left\|P_{r}^{m_{i}}\right\|=\frac{P_{r}^{m_{i}}}{\operatorname{Max}\left(P_{r}^{m_{1}}, P_{r}^{m_{2}} \ldots P_{r}^{m_{12}}\right)}
$$

Where $\left\|P_{r}^{m_{i}}\right\|$ is the average of Humidity/Sea Pressure for the month of $m_{i}$ for the region $r$. Here $r$ is Bhubaneswar, State Capital of Odisha, INDIA.

Table 5. Sea Pressure Data for Y12-Y14

\begin{tabular}{|l|l|l|l|}
\hline \multicolumn{1}{|c|}{ Month } & Year 2012 & \multicolumn{1}{c|}{ Year 2013 } & Year 2014 \\
\hline Jan & 29.88 & 29.88 & 30.02 \\
\hline Feb & 29.88 & 29.94 & 29.91 \\
\hline Mar & 29.82 & 29.84 & 29.89 \\
\hline Apr & 29.72 & 29.74 & 29.77 \\
\hline May & 29.6 & 29.58 & 29.68 \\
\hline Jun & 29.49 & 29.51 & 29.53 \\
\hline Jul & 29.51 & 29.48 & 29.51 \\
\hline Aug & 29.56 & 29.57 & 29.61 \\
\hline Sep & 29.66 & 29.65 & 29.67 \\
\hline Oct & 29.83 & 29.77 & 29.85 \\
\hline Nov & 29.88 & 29.92 & 29.91 \\
\hline Dec & 29.93 & 29.96 & 29.96 \\
\hline
\end{tabular}

The normalized Sea Pressure data calculated from above equation is shown in below table.

Table 6. Sea Pressure Temperature Data for Y12-Y14

\begin{tabular}{|l|l|l|l|}
\hline Month & \multicolumn{1}{|c|}{ Norm Y12 } & \multicolumn{1}{|c|}{ Norm Y13 } & \multicolumn{1}{|c|}{ Norm Y14 } \\
\hline Jan & 0.998329 & 0.99733 & 1 \\
\hline Feb & 0.998329 & 0.999332 & 0.996335776 \\
\hline Mar & 0.996325 & 0.995995 & 0.995669554 \\
\hline Apr & 0.992984 & 0.992657 & 0.991672219 \\
\hline May & 0.988974 & 0.987316 & 0.988674217 \\
\hline Jun & 0.985299 & 0.98498 & 0.983677548 \\
\hline Jul & 0.985967 & 0.983979 & 0.983011326 \\
\hline Aug & 0.987638 & 0.986983 & 0.986342438 \\
\hline Sep & 0.990979 & 0.989653 & 0.988341106 \\
\hline Oct & 0.996659 & 0.993658 & 0.994337109 \\
\hline Nov & 0.998329 & 0.998665 & 0.996335776 \\
\hline Dec & 1 & 1 & 0.998001332 \\
\hline
\end{tabular}

\subsection{Rainfall Data}

The tabular data is captured from [14] month-wise for the region of Bhubaneswar, State capital of Odisha. The year wise normalized Precipitation/Rainfall data calculated as per the following formula.

$$
\left\|R_{r}^{m_{i}}\right\|=\frac{R_{r}^{m_{i}}}{\operatorname{Max}\left(R_{r}^{m_{1}}, R_{r}^{m_{2}} \ldots R_{r}^{m_{12}}\right)}
$$

Where $\left\|R_{r}^{m_{i}}\right\|$ is the average of Precipitation/Rainfall for the month of $m_{i}$ for the region $r$. Here $r$ is Bhubaneswar, State Capital of Odisha, INDIA.

Table 7. Rainfall Data for Y12-Y14

\begin{tabular}{|l|l|l|l|}
\hline \multicolumn{1}{|c|}{ Month } & Year 2012 & Year 2013 & Year 2014 \\
\hline Jan & 0 & 0 & 0 \\
\hline Feb & 0 & 0 & 0.04 \\
\hline Mar & 0 & 0 & 0.08 \\
\hline Apr & 0.06 & 0.05 & 0.01 \\
\hline May & 0.03 & 0.05 & 0.18 \\
\hline Jun & 0.15 & 0.27 & 0.17 \\
\hline Jul & 0.3 & 0.26 & 0.27 \\
\hline Aug & 0.15 & 0.07 & 0.26 \\
\hline Sep & 0.15 & 0.38 & 0.23 \\
\hline Oct & 0.03 & 0.08 & 0.05 \\
\hline Nov & 0.12 & 0 & 0 \\
\hline Dec & 0 & 0 & 0.03 \\
\hline
\end{tabular}

The normalized Rainfall data calculated from above equation is shown in below table.

Table 8. Rainfall Temperature Data for Y12-Y14

\begin{tabular}{|l|l|l|l|}
\hline Month & Norm Y12 & Norm Y13 & Norm Y14 \\
\hline Jan & 0 & 0 & 0 \\
\hline Feb & 0 & 0 & 0.148148 \\
\hline Mar & 0 & 0 & 0.296296 \\
\hline Apr & 0.2 & 0.131579 & 0.037037 \\
\hline May & 0.1 & 0.131579 & 0.666667 \\
\hline Jun & 0.5 & 0.710526 & 0.62963 \\
\hline Jul & 1 & 0.684211 & 1 \\
\hline Aug & 0.5 & 0.184211 & 0.962963 \\
\hline Sep & 0.5 & 1 & 0.851852 \\
\hline Oct & 0.1 & 0.210526 & 0.185185 \\
\hline Nov & 0.4 & 0 & 0 \\
\hline Dec & 0 & 0 & 0.111111 \\
\hline
\end{tabular}

\section{SIMULATION ANALYSIS}

Here the normalized data are fed to the neural network NGC Engine algorithm and ran the algorithm with multiple epochs. It is noticed that the error percentage is tremendously reduced and shows a great improvement over the classical regression models. 


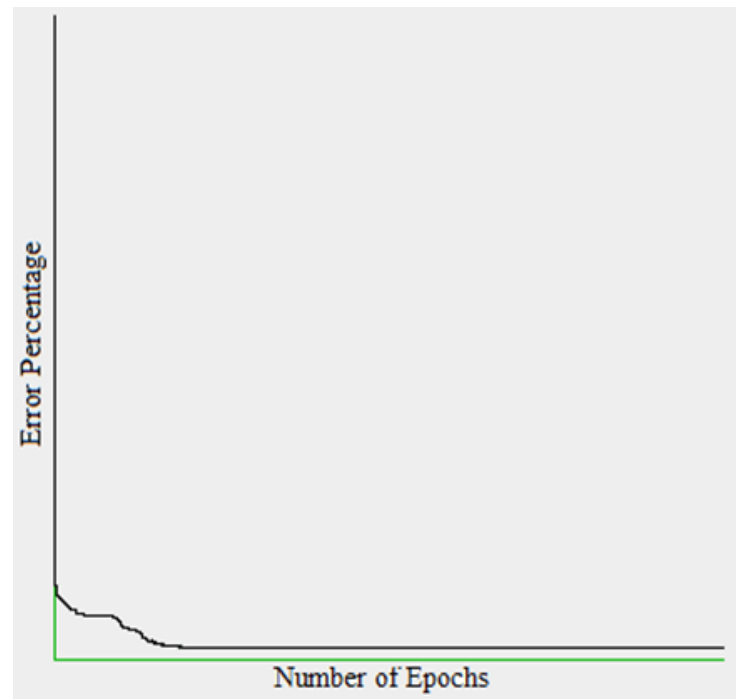

Fig 3: 2012-Epochs 100000 with 5.66\% error

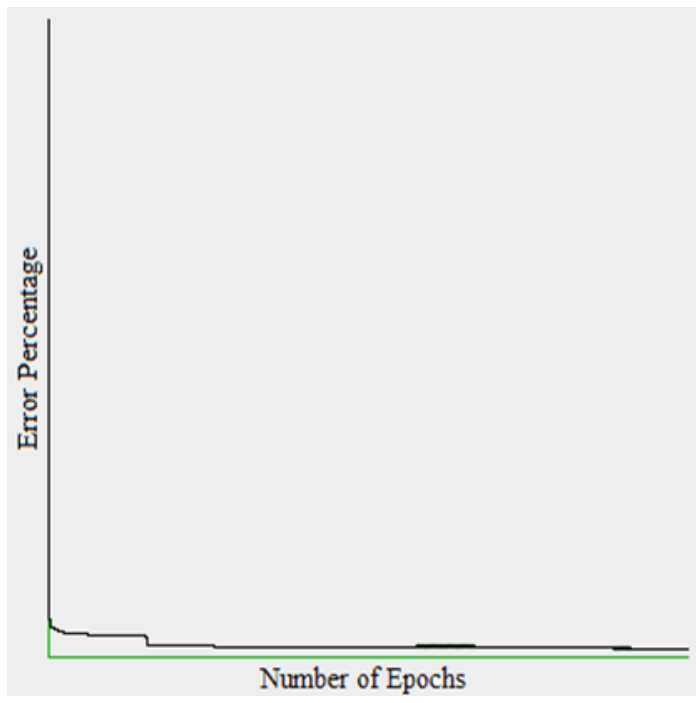

Fig 4: 2012-Epochs 10000000 with $1.95 \%$ error

The error calculated through the Neural Network based model for the year 2012 is shown in figure 3 and 4 . The number of epochs ran for the 2012 data is 100000 and 10000000 and the mean absolute percent error is 5.66 and 1.95. The more epochs it ran, it gets more accuracy with respect to expected result.

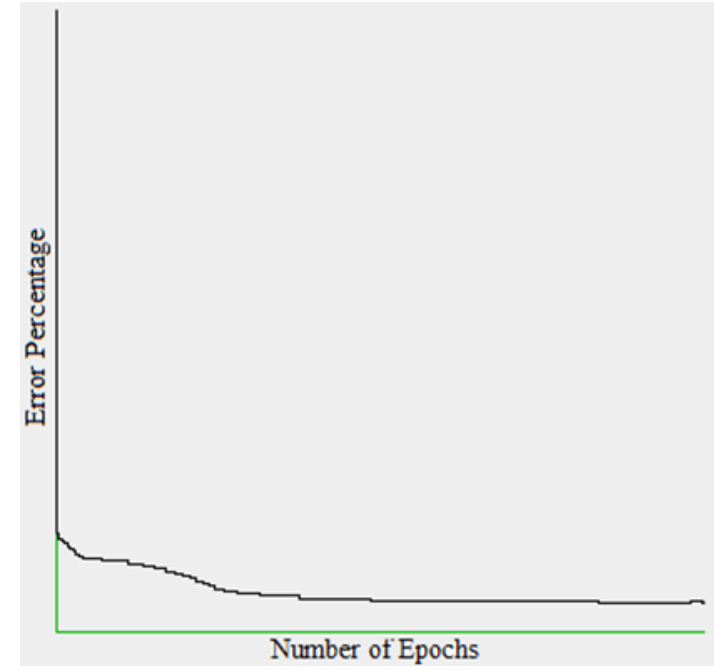

Fig 5: 2013 - Epochs 100000 with $11.87 \%$ error

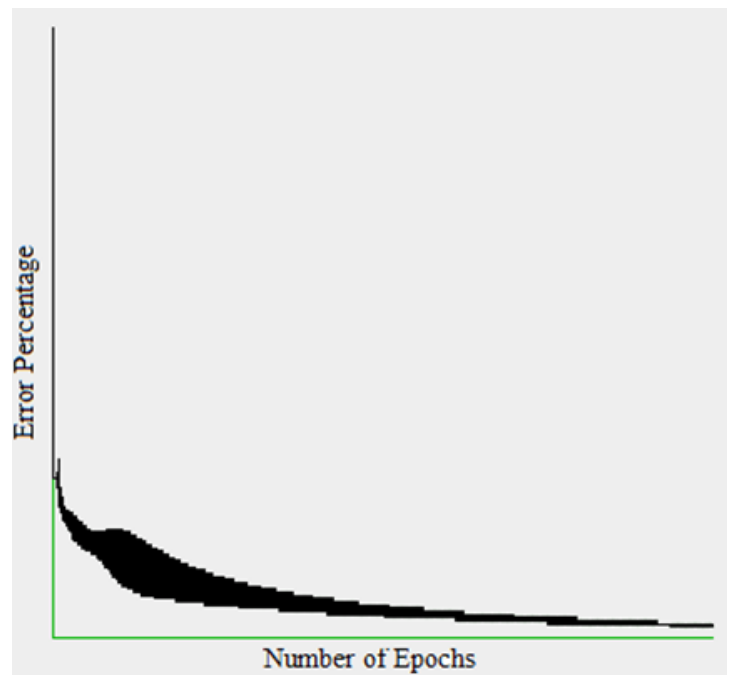

Fig 6: 2013 - Epochs 10000000 with 3.09\% error

Similarly, the model is ran to evaluate the neural network output for the year 2013 and results shown in figure 5 and 6 . The error percentage is $11.87 \%$ for 100000 epochs and $3.09 \%$ for the 10000000 epochs as shown in figure. Though it is seen that more convergence variations for 2012 data with 10000000 epochs but the function finally converges to provide a result of $3.09 \%$ of error accuracy.

Similar simulated exercise also applied for the year 2014 data as shown in figure 7 and 8 . With 100000 epoch the error rate comes down to $9.90 \%$ while with epochs 10000000 epochs the error rate reduced to $6.48 \%$ accuracy.

Here in the below figure, it is provided the evaluated result for the 3 years data and had shown that the error rate is reduced with more number of epochs. 


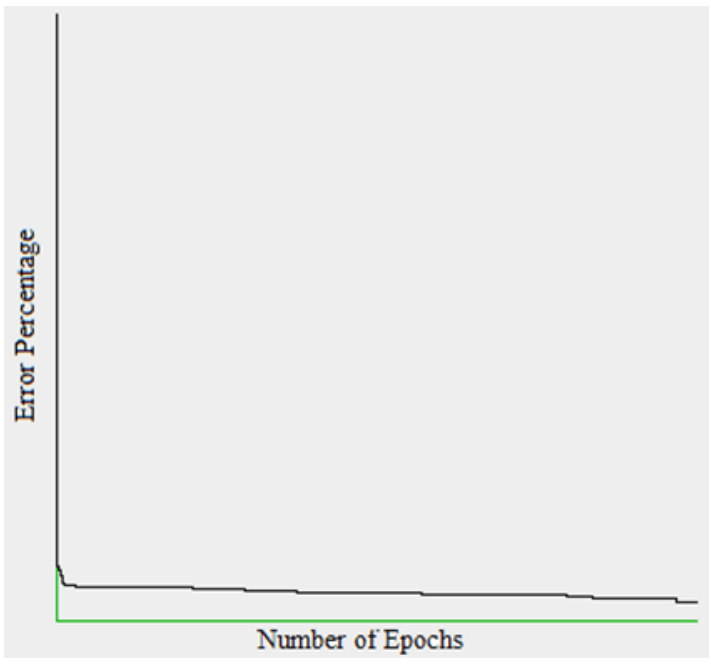

Fig 7: 2014 - Epochs 100000 with $9.90 \%$ error

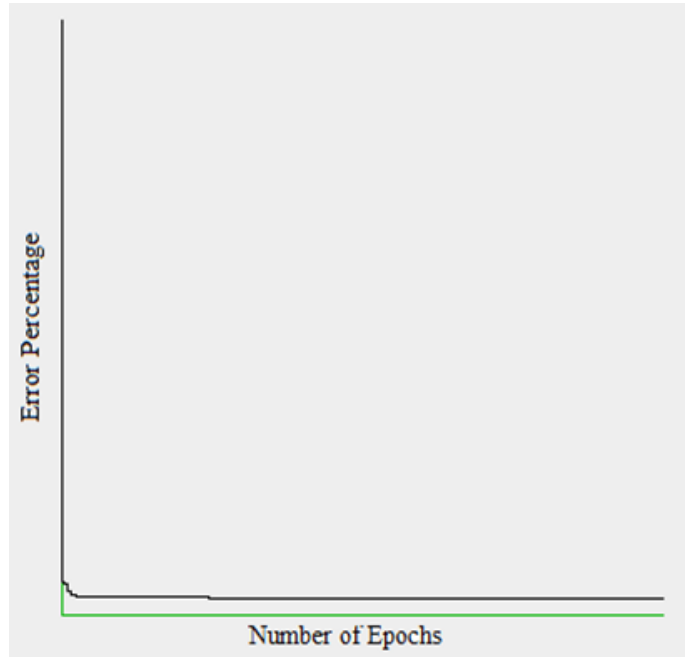

Fig 8: 2014 - Epochs 10000000 with 6.48\% error

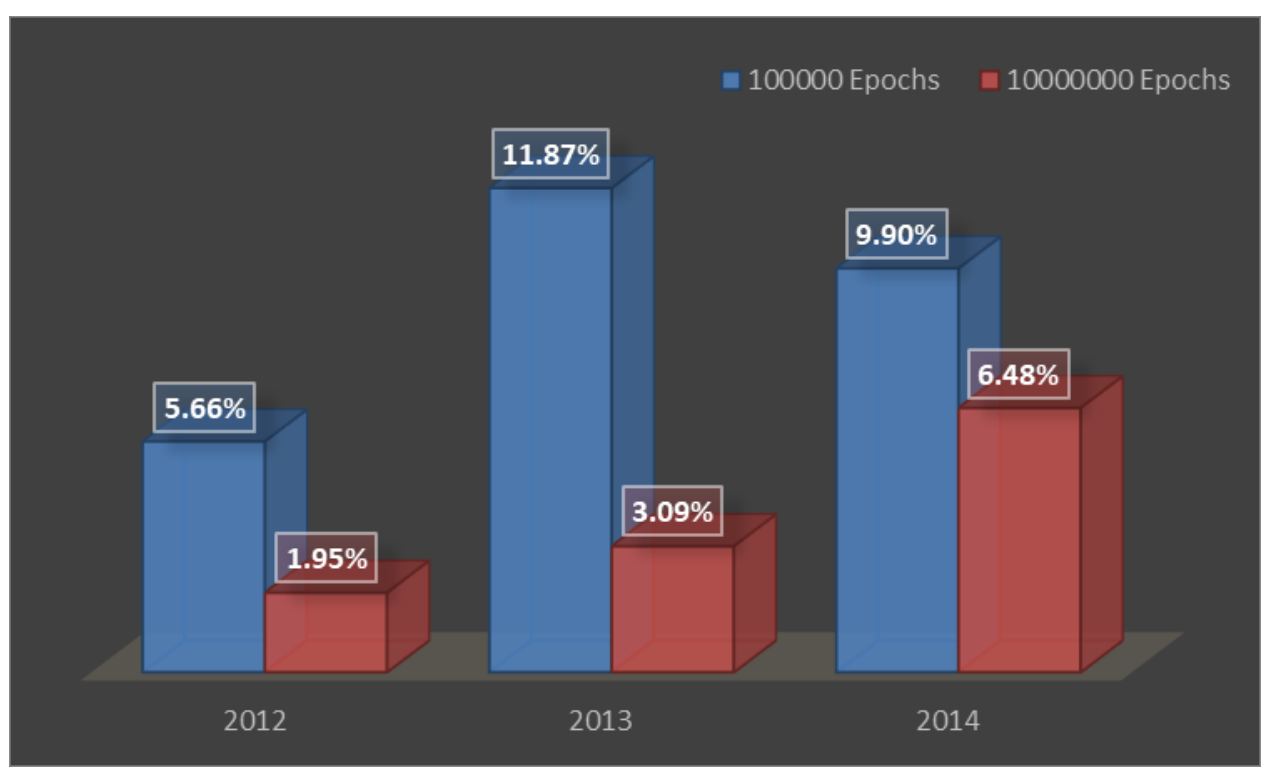

Fig 9: Neural Network Error Reduction with maximizing number of Epochs

This means that the neural network function is converging with the environment data i.e. temperature, humidity (sea pressure) and rain fall. This proves that the environment factors have the direct effect on the natural gas consumption and hence the neural network prediction algorithm i.e. back propagation algorithm converges and reduces the error rate. Figure 10 provides a clear distinction of the reduction of errors as the epochs number increases. The same trends have been identified in 3 years of data.

The below tabular data represents the error percentage of different classical methods i.e. moving average, smoothing analysis and least square methods along with the neural network based natural gas consumption model data. In all the year, it's seen that the neural network based evaluated data is with more accuracy than the other classical model data.
Table 8. Rainfall Temperature Data for Y12-Y14

\begin{tabular}{|l|l|l|l|}
\hline Models & $\mathbf{2 0 1 2}$ & $\mathbf{2 0 1 3}$ & $\mathbf{2 0 1 4}$ \\
\hline Moving Average & $4.45 \%$ & $5.40 \%$ & $7.70 \%$ \\
\hline Smoothing Analysis & $3.39 \%$ & $6.86 \%$ & $8.98 \%$ \\
\hline Least Square & $2.96 \%$ & $6.81 \%$ & $8.32 \%$ \\
\hline NN-NGC Model & $1.95 \%$ & $3.09 \%$ & $6.48 \%$ \\
\hline
\end{tabular}

Figure 10 is the graphical representation of the above tabular data. In the year 2012, proposed neural network model results has $2.5 \%$ more accuracy than moving average, $1.45 \%$ more accuracy than Smoothing Analysis method, and 1.01\% of more accuracy than least square method.

Similarly, for the year 2013, propose neural network model has $2.31 \%$ more accuracy, $3.77 \%$ more accuracy than smoothing analysis model, $3.72 \%$ more accuracy than Least Square methods. For the year 2014, the proposed neural network model has $1.22 \%$ more accuracy than moving average, $2.5 \%$ more accuracy than smoothing analysis model and $1.84 \%$ more accuracy than least square method. 


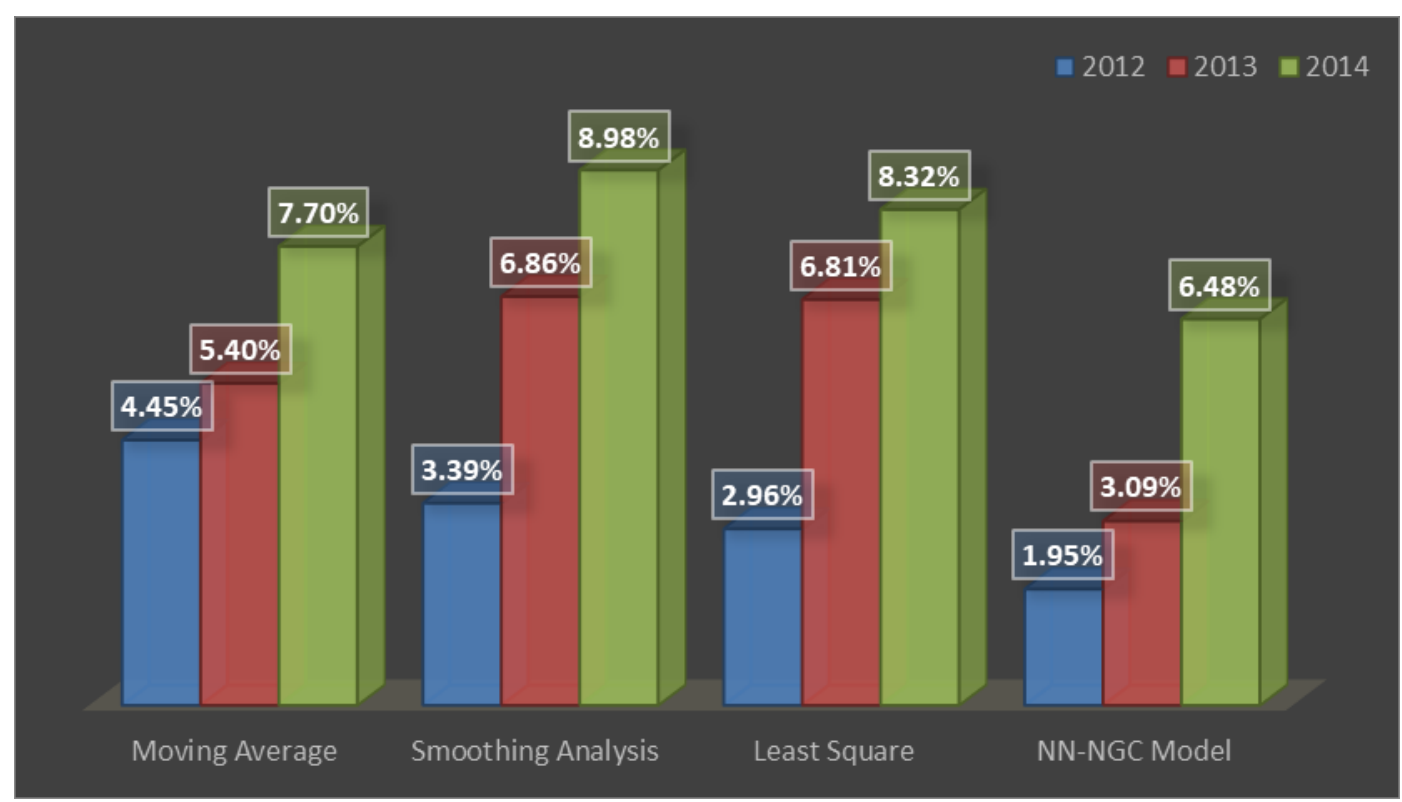

Fig 10: Comparison of Classical Model with Proposed Neural Network based Forecasting Model

\section{CONCLUSION}

Neural Network model is a widely accepted methodology to match the patterns. In this article, a neural network based natural gas consumption computation model is proposed, where neural network method is applied to match the natural gas consumption pattern. The data conciliation to converge the result data and making the result data to compare with the expected data and then weight updating had provided maximum accuracy for this proposed model. The result shows that the environmental factors e.g. temperature, humidity and the rainfall have the true effect on the natural gas consumption. Three classical model data has been compared with the results with the proposed neural network based model and found that the forecasting error reduced in the range of $1.01 \%-2.50 \%$. this is an outstanding improvement in the natural gas consumption forecasting model. The other neural network model, artificial resonance theory and fuzzy logic implementation to gain more accuracy on the forecasting is the future scope of this research article.

\section{REFERENCES}

[1] Pradhan, P.K., Nayak, B., Dhal S.K., 2016. Time Series Data Prediction of Natural Gas Consumption Using Arima Model. International Journal of Information Technology \& Management Information System, 7(3). $1-7$.

[2] Hongwei, M., Yonghe W., 2009. Grey Predictive on Natural Gas Consumption and Production in China. Web Mining and Web-based Application.

[3] Pradhan, P.K., Dhal, S.K.,2015. A Survey of Different Prediction Models \& Role of Artificial Neural Networks for Natural Gas Consumption. International Journal of
Science and Research (IJSR), 4(11).1325-1328

[4] https://www.eia.gov/energyexplained/index.cfm

[5] XGilardoni, A., Demand for Natural Gas: Trends and Drivers in The World Market for Natural Gas Springer Berlin Heidelberg. 39-60

[6] http://www.weatherbase.com/weather/countryall.php3

[7] Brown, R.H., Vitullo, S.R., Corliss, G.F.,2015. Detrending daily natural gas consumption series to improve short-term forecasts in Power \& Energy. IEEE Society General Meeting.

[8] https://www.numbeo.com/cost-ofliving/country_price_rankings?itemId $=105$

[9] https://www.studentenergy.org/topics/natural-gas

[10] Licheng, S., Ronghua, H., 2009. Study on the relationship between the energy consumption and economic system of Jiangsu Province base on grey relational analysis. IEEE Grey Systems and Intelligent Services,

[11] https://en.wikipedia.org/wiki/List_of_countries_by_natur al_gas_consumption

[12] http://ahnutritiontherapy.com/338/foods-to-fighthumidity

[13] https://www.epa.gov/climate-impacts/climate-impactsagriculture-and-food-supply.

[14] https://www.wunderground.com/history/airport/VEBS/2 012/1/1/MonthlyHistory.html 